\title{
Revascularization of Atherosclerotic Renal Artery Stenosis for Chronic Heart Failure Versus Acute Pulmonary Oedema
}

DOI:

10.1111/nep.13038

\section{Document Version}

Accepted author manuscript

Link to publication record in Manchester Research Explorer

\section{Citation for published version (APA):}

Green, D., Ritchie, J. P., Chrysochou, C., \& Kalra, P. A. (2017). Revascularization of Atherosclerotic Renal Artery Stenosis for Chronic Heart Failure Versus Acute Pulmonary Oedema. Nephrology. https://doi.org/10.1111/nep.13038

\section{Published in:}

Nephrology

\section{Citing this paper}

Please note that where the full-text provided on Manchester Research Explorer is the Author Accepted Manuscript or Proof version this may differ from the final Published version. If citing, it is advised that you check and use the publisher's definitive version.

\section{General rights}

Copyright and moral rights for the publications made accessible in the Research Explorer are retained by the authors and/or other copyright owners and it is a condition of accessing publications that users recognise and abide by the legal requirements associated with these rights.

\section{Takedown policy}

If you believe that this document breaches copyright please refer to the University of Manchester's Takedown Procedures [http://man.ac.uk/04Y6Bo] or contact uml.scholarlycommunications@manchester.ac.uk providing relevant details, so we can investigate your claim.

\section{OPEN ACCESS}




\section{Revascularization of atherosclerotic renal artery stenosis for}

\section{chronic heart failure versus acute pulmonary oedema}

Darren Green MRCP PhD ${ }^{\mathrm{a}, \mathrm{b}}$, James P Ritchie MRCP PhD ${ }^{\mathrm{b}}$, Constantina Chrysochou MRCP $\mathrm{PhD}^{\mathrm{b}}$, Philip A Kalra FRCP MD ${ }^{\mathrm{a}, \mathrm{b}}$

${ }^{a}$ Institute of Cardiovascular Sciences, University of Manchester, Manchester Academic

Health Sciences Centre, UK.

${ }^{b}$ Vascular Research Group, Salford Royal NHS Foundation Trust, Manchester Academic

Health Sciences Centre, UK.

Correspondence: Darren Green,

Consultant Nephrologist,

Department of Renal Medicine, Salford Royal Foundation Trust,

Salford, UK M6 8HD

Tel: 00441612060509

Fax: 00441612065998

Email: darrengreen@doctors.org.uk

Running title: $\quad$ RAS revascularization in $\mathrm{HF}$

This article has been accepted for publication and undergone full peer review but has not been through the copyediting, typesetting, pagination and proofreading process which may lead to differences between this version and the Version of Record. Please cite this article as doi: 10.1111/nep.13038 


\begin{abstract}
Aim: To determine whether the apparent benefit of revascularization of renal artery stenosis for "flash" pulmonary oedema extends to heart failure patients without a history of prior acute pulmonary oedema.
\end{abstract}

Methods: A prospective study of patients with renal artery stenosis and heart failure at a single centre between $1^{\text {st }}$ January 1995 and $31^{\text {st }}$ December 2010. Patients were divided into those with and without previous acute pulmonary oedema / decompensation. Survival analysis compared revascularization versus medical therapy in each group using Cox regression adjusted for age, eGFR, blood pressure, and co-morbidities.

Results: There were 152 patients: $59 \%$ male, $36 \%$ diabetic, age $70 \pm 9$ years, eGFR $29 \pm 17 \mathrm{~mL} / \mathrm{min} / 1.73 \mathrm{~m}^{2} .52$ had experienced previous acute pulmonary oedema (34\%), whereas 100 had no previous acute pulmonary oedema (66\%). The revascularization rate was $31 \%$ in both groups.

For heart failure without previous acute pulmonary oedema, the hazard ratio for death after revascularization compared to medical therapy was $0.76(0.58-0.99, \mathrm{p}=0.04)$. In heart failure with previous acute pulmonary enema, the hazard ratio was $0.73(0.44-1.21, \mathrm{p}=0.22)$.

For those without previous acute pulmonary oedema, the hazard ratio for heart failure hospitalization after revascularization compared to medical therapy was 1.00 (0.17-6.05, $\mathrm{p}=1.00)$. In those with previous acute pulmonary oedema, it was $0.51(0.08-3.30, \mathrm{p}=0.48)$.

Conclusions: The benefit of revascularization in heart failure may extend beyond the current indication of acute pulmonary oedema. However, findings derive from an observational study.

Keywords: atherosclerosis, chronic kidney disease, heart failure, hypertension, renal artery stenosis 


\section{Introduction}

The co-existence of cardiac and renal disease is common, and associated with poorer prognosis ${ }^{1}$. Fifty-five percent of chronic heart failure patients have stage 3, 4, or 5 chronic kidney disease $(\mathrm{CKD})^{2}$, and both mortality and cardiovascular events increase as estimated glomerular filtration rate (eGFR) declines. One cause of concurrent CKD in heart failure is atherosclerotic renovascular disease causing renal artery stenosis (RAS) $)^{3,4} .34 \%$ of patients suffering acute decompensation of heart failure requiring hospital admission have $\operatorname{RAS}^{5}, 38 \%$ of RAS patients have heart failure ${ }^{6}$, and $12 \%$ of all RAS diagnoses present with "flash pulmonary oedema"7. Flash pulmonary oedema is a poorly defined term and the clinical presentation is no different to that of acute pulmonary oedema (APO) in decompensation of heart failure in other settings ${ }^{4}$. Indeed, "flash" pulmonary oedema was not a term used when this phenomenon was first described in association with $\mathrm{RAS}^{8}$.

Animal models of RAS have demonstrated a potential causative mechanism in which renal artery ligation leads to over-activation of the renin-angiotensin pathway, and consequent salt and water retention ${ }^{9}$. The earliest clinical case series of revascularization of RAS as therapy for APO noted that profound weight loss of up to $4 \mathrm{~kg}$, due to diuresis after revascularization, was a common feature $e^{8,10,11}$. A more recent case report found a drop in circulating angiotensin 2 levels from $0.61 \mathrm{ng} / \mathrm{mL}$ before to $0.16 \mathrm{ng} / \mathrm{mL}$ one day postrevascularization ${ }^{12}$. Up to $75 \%$ of RAS patients have echocardiographic evidence of left ventricular hypertrophy, often with significant diastolic dysfunction ${ }^{13}$. This presents a case for RAS playing a significant role in inducing cardiac remodelling with subsequent development of heart failure, rather than the relationship being simply limited to coincidental renal atheroma alongside ischaemic cardiomyopathy. 
Although two recent randomized controlled trials $(\mathrm{RCT})$ of $>800$ patients, as well as meta-analyses, have failed to show a benefit of renal artery revascularization over medical therapy for RAS as first line therapy in allcomers ${ }^{14-16}$, patients with HF were in the minority in the RCT and those with APO non-existent in at least one trial which excluded patients with a previously described indication for intervention ${ }^{14}$. Nevertheless, flash pulmonary oedema remains a documented indication for revascularization ${ }^{17}$. This is based on historical case series, and is supported by a recent observational study in which the hazard ratio for death in patients with flash pulmonary oedema undergoing revascularization was 0.4 (95\% CI, 0.2$0.9 ; P=0.01)$ compared to treatment with medical therapy ${ }^{7}$.

Whether the apparent benefit of renal artery revascularization over medical therapy extends to heart failure without APO (i.e. without previous acute decompensation) is uncertain, but a similar theoretical benefit of revascularization exists as that for APO. Given the high prevalence of atherosclerotic RAS in heart failure - both are diseases of ageing - this is a potentially valuable therapeutic option. In a case series of 100 patients with heart failure, RAS, and hypertension, those who underwent revascularization suffered fewer hospitalizations and lower NYHA scores than gender matched controls managed medically ${ }^{18}$. However, this study did not adjust for statistical and numerical differences in age and comorbidities between the groups, nor whether APO was a presenting feature in any or all of the revascularized cases.

The intention of this study was to compare adjusted outcomes for renal artery revascularization versus medical therapy for RAS in the setting of heart failure, in a large prospectively collected dataset. More uniquely, patients with heart failure were sub-divided into those with and without prior APO to determine whether the benefit of revascularization for APO patients noted previously may also be seen in chronic heart failure without previous 
APO. Also, phenotype data were compared between revascularized and medically managed patients to determine whether these groups were comparable.

Such a comparison is potentially viable in an observational setting because of variation in clinical practice associated with RAS management ${ }^{19}$. This is based to some extent on the lack of randomized trial data to underpin generally acknowledged indications for revascularization including "flash" pulmonary oedema, as well as hypertension and rapid decline in renal function. For example, in 2010 in the United States fewer than half the number of renal revascularization procedures for RAS were performed compared to the year 2000.

The primary aim of the study was therefore to investigate whether patients with ARVD and chronic heart failure without any previous episode of APO may benefit from renal revascularization. A secondary aim was to compare outcome and the relative impact of revascularization in ARVD-HF with and without previous APO.

\section{Materials and Method}

This was retrospective analysis of a prospectively collected observational study of adult patients with unilateral or bilateral RAS $\geq 50 \%$ managed in a single nephrology secondary care centre between January 1995 and December 2010. Ethical approval was granted by the local Research Ethics Committee, and the study complied with the Declaration of Helsinki. A diagnosis of RAS was made by CT, MR or direct angiography. Nonatherosclerotic causes of RAS were excluded. Decisions to treat for both medical and revascularization groups were made by the attending physician based upon prevailing opinion (as opposed to being protocol driven), or in some cases randomization of patients into 
contemporary RCT. All revascularization procedures were by angioplasty \pm stenting. There were no surgical interventions.

Data were recorded for degree of stenosis (patency score), indication for revascularization, laboratory data from the date of patient entry into the study, prescribed medication at baseline, and cardiovascular co-morbidities. A diagnosis of heart failure was based on the clinical history including that of previous hospitalization, physical examination and radiographic evidence, with echocardiographic evidence of diastolic dysfunction or left ventricular ejection fraction (LVEF) $<50 \%$. Diastolic dysfunction was defined as abnormalities in at least 2 of: Transmitral E:A velocities ratio; mitral flow E wave deceleration time; and isovolumetric relaxation time. APO was defined as hospitalization for acute pulmonary oedema in the presence of atherosclerotic RAS and irrespective of aetiology i.e. including decompensation of heart failure. Whether patients had previous APO events was determined from history taking, hospital medical records (ours is a secondary care centre for cardiology as well as nephrology), and primary care records where available. RAS patency score was defined as $\%$ diameter right renal artery patent $+\%$ diameter left renal artery patent, and occlusive RAS was defined as unilateral or bilateral RAS where all lesions demonstrate complete luminal occlusion.

The study start date was taken as date of first clinic visit for medically managed patients, or date of attempted revascularization. Analysis was performed on an intention to treat basis. Patients with a diagnosis of heart failure were selected for this analysis and were divided into those with and without a previous episode of APO.

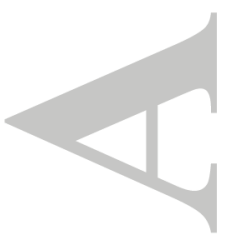


End points were time to: 1) all-cause mortality; 2) hospitalization for heart failure including for APO, and; 3) fatal or non-fatal cardiovascular event (myocardial infarction, coronary revascularization, hospitalization for acute pulmonary oedema or other management of heart failure, hospitalization with arrhythmia, stroke, or non-traumatic intracranial bleed).

Comparisons of baseline patient characteristics were made using chi square tests for binary variables and unpaired t-tests for continuous variables. Survival analyses were performed using a Cox proportional hazard model, adjusted for age, eGFR, systolic blood pressure, coronary artery disease (previous myocardial infarction, coronary revascularisation or bypass, or medically managed angina), smoking, diabetes mellitus, and RAS patency score. Significance was set at $\mathrm{p} \leq 0.05$ (2-sided).

To test the existence of selection bias for revascularization procedures in influencing outcome, we also determined the adjusted hazard ratio (HR) for mortality in patients without heart failure who had not been randomized into the ASTRAL or CORAL trials who had undergone revascualrization compared to medical therapy. We then compared the HR here with data from a recent meta-analysis of mortality outcomes in revascularization versus medical therapy for RAS. This meta-analysis showed no difference in outcome between treatment $\operatorname{arms}^{20}$. Therefore, any difference in outcome between treatments in non-heart failure patients in our study would likely reflect bias, whereas if our findings were consistent with those of the meta-analysis it would argue in favour of the variation in clinical practice and our statistical adjustments overcoming such bias. 


\section{Results}

There were 152 heart failure patients with RAS. $59 \%$ were male, $36 \%$ diabetic, the mean age was $70 \pm 9$ years, eGFR $29 \pm 17 \mathrm{~mL} / \mathrm{min} / 1.73 \mathrm{~m}^{2} .52$ had previous APO at presentation (34\%). Comparisons with a statistical difference were as follows: patients without previous APO who were revascularized had a lower patency score than those managed medically ( $73 \pm 50$ versus $94 \pm 46, \mathrm{p}=0.04)$, and patients with previous APO who were revascularized were younger than those managed medically (64 \pm 7 versus $72 \pm 7$ years, $\mathrm{p}=0.01)$. Table 1 shows phenotype data and a full breakdown of between group comparisons for revascularization versus medical therapy in each of heart failure patients with and without previous APO.

The proportion of patients undergoing revascularization was $31 \%$ for patients with heart failure but not APO (n=31), and also $31 \%$ for heart failure patients with APO $(n=16)$. There were 5 failed procedures (HF no APO n=3 [10\%], HF with APO n=2 [13\%]). For patients with heart failure but no APO, the most common indications for revascularization were hypertension (32\%) and heart failure (19\%). For patients with APO, the APO was the indication for revascularization in the majority. Table 2 shows a full list of primary indications for revascularization for each patient group.

The mean follow up time was $52 \pm 42$ months during which there were 118 deaths (78\%), and 59 cardiovascular event end points (39\%), of which 13 (22\% of cardiovascular events) were hospitalization for heart failure. For heart failure without APO the HR for death compared to heart failure with APO was $1.91(1.55-2.54, \mathrm{p}<0.001)$.

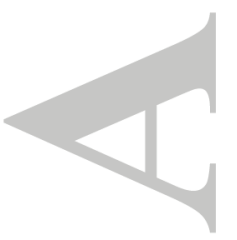


For heart failure patients without previous APO, the adjusted HR for death in those revascularized compared to receiving medical therapy was $0.76(0.58-0.99, \mathrm{p}=0.04)$. This was numerically similar in patients with APO (HR 0.73 [0.44 - 1.21], $\mathrm{p}=0.22$ ) but nonsignificant. Survival curves for these data are shown in figure 1.

For patients without previous APO, the adjusted HR for future heart failure hospitalization in revascularized compared to medically treated patients was $1.00(0.17-6.05$, $\mathrm{p}=1.00)$. For patients with previous APO the HR was $0.51(0.08-3.30, \mathrm{p}=0.48)$.

Revascularization appeared to have little impact on overall cardiovascular events outside of the numerical difference in heart failure hospitalization. For patients without previous APO, the adjusted HR for cardiovascular events in revascularized compared to medically treated patients was $0.98(0.44-2.18, \mathrm{p}=0.96)$. For patients with previous APO the HR was $0.62(0.31-1.27, \mathrm{p}=0.19)$. A summary of the HR for this and other end points is shown in table 3. A breakdown of all causes of death in different patient groups and the diagnoses for cardiovascular event end points is shown in table 4. In patients without prior APO who were managed medically, $39 \%$ of patients died from cardiac causes during follow up compared with $16 \%$ in revascularized patients. In patients with prior APO, there was a similar difference of $35 \%$ versus $17 \%$. There was no reduction in death due to other cardiovascular or non-cardiovascular causes in either of the revascularized groups. The numerical differences described did not reach statistical significance. The numerical differences described did not reach statistical significance.

In order to provide some external validation to our non-randomised observational study, the adjusted HR for all-cause mortality in revascularized patients in non-HF patients was compared with that in a previous meta-analysis ${ }^{20}$. There were 459 non-heart failure RAS patients with a mean age of $70 \pm 9$ years. $56 \%$ were male, with eGFR $35 \pm 19$ 
$\mathrm{mL} / \mathrm{min} / 1.73 \mathrm{~m}^{2}$. In our study the HR was $0.92(0.62-1.14, \mathrm{p}=0.66)$ compared with 0.91 $(0.75-1.11, \mathrm{p}=0.98)$ in the meta-analysis.

\section{Discussion}

In this study of 152 patients with co-existent heart failure and RAS, the phenotype of patients undergoing revascularization was broadly comparable to those managed medically. This reflects the variation in practice between clinicians for such patients given that evidence for management of RAS in heart failure and APO was not based on RCT data ${ }^{17,19}$, and also reflecting the long duration of this prospective study. Nonetheless, despite these similarities, the presented analyses were adjusted for demographic and co-morbid data in an attempt to minimise the effect of hidden bias in observational studies such as this. Our efforts are supported by the comparison of mortality in our non-HF patients with meta-analysis of RCT. However, the possibility of bias in HF sub-groups remains and this is the main limitation affecting interpretation. The analyses were performed in a patient group in whom detailed clinical and laboratory data have been prospectively and studiously collected over 15 years. Whilst the single centre patient management, rigor of data collection, and real-life setting are strengths, the lack of true randomization of patients for revascularization is a weakness that cannot be overcome outside of an RCT.

The key finding in this study was the significant reduction in all-cause mortality for patients with heart failure who had never had a previous presentation with APO. Table 4 demonstrates that this appears to be due to a reduction in death due to cardiac causes. However, this improved survival was not associated with an overall reduction in cardiovascular events. 
In this study, all episodes of acute pulmonary oedema in the setting of co-existent RAS were considered to be comparable to "flash pulmonary oedema" described in other studies given that there is no clear diagnostic difference between "flash" and "acute" pulmonary oedema. This contrasts with our previous analysis in which the term flash pulmonary oedema excluded episodes in those patients with established severe systolic impairment ${ }^{7}$. In that study, patients with occlusive disease were also excluded, and revascularization was associated with a greater reduction in mortality $(\mathrm{HR}=0.4$ [0.2-0.9], $\mathrm{p}=0.01)$ compared to the present analysis, and the mortality advantage was statistically significant. That only $31 \%$ of acute pulmonary oedema patients in this study were revsacularized serves to demonstrate the differences in clinical practice associated with RAS, and the partial randomization effect this produces.

There was also a numerical reduction in hospitalization due to heart failure, specific to patients with previous APO. This is consistent with previous studies. Kane et al found a fivefold reduction in heart failure hospitalizations amongst 50 patients who were revascularized versus 50 gender matched medically managed controls with heart failure and RAS ${ }^{18}$. However, in that study, there was no difference in mortality between arms. Another small RCT has shown reduction in left ventricular mass after 12 months following revascularization in a cohort of 84 RAS patients with coronary artery disease ${ }^{21}$. Despite some differences in the outcomes measured, this and other studies provide support for, or at least do not counter, the possibility that revascularization for RAS in the presence of heart failure leads to improved outcome irrespective of the presence of APO. The mechanistic theory behind this beneficial clinical outcome is provided by the association of RAS with excess circulating angiotensin $2^{12}$ and salt and water retention in both animal models and cases in $\operatorname{man}^{9,10}$, and evidence of progressive abnormal cardiac remodelling in patients with $\operatorname{RAS}^{13,22}$. These pathological 
changes have been shown to regress, at least partially, after revascularization, albeit in selected case series ${ }^{12,21,23}$.

Patients who had previous APO events had a numerically higher LVEF and systolic blood pressure, but were less likely to have had a previous MI. We offer two possible explanations which may both contribute to this finding. Firstly, the history of fewer MIs and more preserved systolic function in those patients with previous APO may indicate a survival bias. Patients with heart failure who have coronary artery disease, systolic heart failure and previous decompensation are likely to die earlier and therefore be under-represented in the study. Second, the higher blood pressure and preserved systolic function in these APO patients may demonstrate a mechanistic association between the ARVD and APO. Patients with ARVD typically have preserved systolic function, diastolic dysfunction and hypertension $^{13}$. Patients at extremes of this phenotype are likely to be those who suffer APO.

It is well established, albeit in observational settings such as this, that APO patients benefit from renal artery revascularization. We have previously shown reduction in both left ventricular hypertrophy on cardiac MRI after revascularization in such a patient, as well as concurrent lowering of circulating angiotensin II levels ${ }^{12}$. It may also be that these effects contribute to the survival benefit in the chronic heart failure group without prior APO.

Chronic heart failure patients with AVRD are also likely to demonstrate elevated angiotensin II levels and hypertrophic remodelling of the left ventricle. Reduction in these parameters may reduce the likelihood of future cardiovascular events. Supporting this, as seen in table 4, we note that fewer died from a cardiac cause (rather than specifically heart failure) in nonAPO patients who were revascularized compared to those managed medically (16\% versus $39 \%$ ). 
The more preserved LVEF in the APO patients highlights that there is often disconnect between severity of heart failure symptoms and LVEF, particularly with HFPEF (heart failure with preserved ejection fraction). NHYA score may provide useful information in ARVD-HF patients but was not recorded as part of this study.

Despite the inconsistency of its definition, flash pulmonary oedema is currently an agreed indication for revascularization for RAS based on data from very small cohorts and selective historical cases studies. Accepting the limitations of this study, this finding, coupled with the findings of other studies discussed above, make the case for further investigation into extending the renal revascularization indication to all RAS patients with heart failure, irrespective of presentation. However, given the potential cost implications of the high coexistent prevalence of heart failure and RAS, the neutral results of ASTRAL and CORAL making RAS screening less likely in heart failure, and the fact that revascularization can be associated with significant morbidity in some patients, revascularization in this clinical situation is unlikely to become routine. Perhaps, therefore, an RCT of renal artery revascularization versus medical therapy in heart failure must be pursued for a more conclusive guideline to be produced.

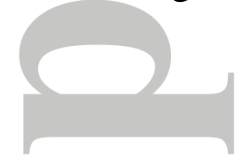

\section{Acknowledgements}

We thank the patients of Salford Royal Hospital for their participation in this study.

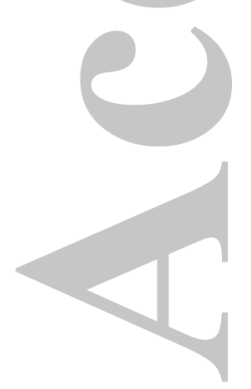




\section{References}

1. Go AS, Chertow GM, Fan D, McCulloch CE, Hsu CY. Chronic kidney disease and the risks of death, cardiovascular events, and hospitalization. N Engl J Med. 2004;351:1296305.

2. American Heart Association. Heart Disease and Stroke Statistics - 2013 Update. American Heart Association, Dallas, TX; 2013.

3. de Silva R, Loh H, Rigby AS, Nikitin NP, Witte KKA, Goode K, Bhandari S, Nicholson A, Clark AL, Cleland JGF. Epidemiology, associated factors, and prognostic outcomes of renal artery stenosis in chronic heart failure assessed by magnetic resonance angiography. Am J Cardiol. 2007;100:273-279.

4. Green D, Kalra PA. The heart in atherosclerotic renovascular disease. Frontiers in Bioscience. 2012;4:856-64.

5. MacDowall P, Kalra PA, O'Donoghue DJ, Waldek S, Mamtora H, Brown K. Risk of morbidity from renovascular disease in elderly patients with congestive cardiac failure. The Lancet. 1998; 352:13-16.

6. Kalra PA, Guo H, Kausz AT, Gilbertson DT, Liu J, Chen S-C, Ishani A, , Collins AJ, Foley RN. Atherosclerotic renovascular disease in United States patients aged 67 years or older: Risk factors, revascularization, and prognosis. Kidney Int. 2005;68:293-301.

7. Ritchie JP, Green D, Chrysochou C, Chalmers N, Foley RN, Kalra PA. High-Risk Clinical Presentations in ARVD: Prognosis and Response to Renal Artery Revascularization. Am J Kidney Dis. 2014;63(2):186-97. 
8. Pickering TG, Devereux RB , James GD, Silane MF, Herman L, Sotelo J, Sos TA, Laragh JH. Recurrent pulmonary oedema in hypertension due to bilateral renal artery stenosis: treatment by angioplasty or surgical revascularisation. Lancet.1988;8610:551-2.

9. Hall J, Granger J, Hester R, Coleman T, Smith Jr M, Cross R. Mechanisms of escape from sodium retention angiotensin II hypertension. Am J Physiol. 1984;246:F627-634.

10. Missouris CG, Buckenham T, Vallance PJ, MacGregor GA. Renal artery stenosis masquerading as congestive heart failure. Lancet. 1993;341(8859):1521-1522.

11. Messina L, Zelenock G, Yao K, Stanley J. Renal revascularization for recurrent pulmonary oedema in patients with poorly controlled hypertension and renal insufficiency: a distinct subgroup of patients with arteriosclerotic renal artery occlusive disease. J Vasc Surg. 1992;15;73-80.

12. Chrysochou C, Schmitt M, Siddals K, Hudson J, Fitchet A, Kalra PA. Reverse cardiac remodelling and renal functional improvement following bilateral renal artery stenting for flash pulmonary ooedema. Nephrol Dial Transplant. 2013;28:479-483.

13. Wright JR, Shurrab AE, Cooper A, Kalra PR, Foley RN, Kalra PA. Left ventricular morphology and function in patients with atherosclerotic renovascular disease. J Am Soc Nephrol. 2005;16:2746-2753.

14. Wheatley K, Ives N, Gray R, Kalra PA, Moss JG, Baigent C, Carr S, Chalmers N, Eadington D, Hamilton G, Lipkin G, Nicholson A, Scoble J on behalf of the ASTRAL investigators. Revascularization versus medical therapy for renal-artery stenosis. $N$ Engl $J$ Med. 2009; 361:1953-1962. 
15. Cooper CJ, Murphy TP, Cutlip DE, Jamerson K, Henrich W, Reid DM, Cohen DJ, Matsumoto AH, Steffes M, Jaff MR, Prince MR, Lewis EF, Tuttle KR, Shapiro JI, Rundback

JH, Massaro JM, D'Agostino RB, Dworkin LD for the CORAL Investigators. Stenting and Medical Therapy for Atherosclerotic Renal-Artery Stenosis. N Engl J Med. 2014; 370:13-22.

16. Kumbhani DJ, Bavry AA, Harvey JE, de Souza R, Scarpioni R, Bhatt DL, Kapadia SR. Clinical outcomes after percutaneous revascularization versus medical management in patients with significant renal artery stenosis: a meta-analysis of randomized controlled trials.

American Heart Association. 2011; 161:622-630.

17. Hirsch AT, Haskal ZJ, Hertzer NR, Bakal CW, Creager MA, Halperin JL, Hiratzka LF, Murphy WRC, Olin JW, Puschett JB, Rosenfield KA, Sacks D, Stanley JC, Taylor LM, White CJ, White J, White RA, Antman EM, Smith SC, Adams CD, Anderson JL, Faxon DP, Fuster V, Gibbons RJ, Hunt SA, Jacobs AK, Nishimura R, Ornato JP, Page RL, Riegel B. American Association for Vascular Surgery/Society for Vascular Surgery, Society for Cardiovascular Angiography and Interventions, Society for Vascular Medicine and Biology, Society of Interventional Radiology, ACC/AHA Task Force on Practice Guidelines. ACC/AHA Guidelines for the Management of Patients with Peripheral Arterial Disease (lower extremity, renal, mesenteric, and abdominal aortic): a collaborative report from the American Associations for Vascular Surgery/Society for Vascular Surgery, Society for Cardiovascular Angiography and Interventions, Society for Vascular Medicine and Biology, Society of Interventional Radiology, and the ACC/AHA Task Force on Practice Guidelines (writing committee to develop guidelines for the management of patients with peripheral arterial disease)--summary of recommendations. J Vasc Interv Radiol. 2006; 17:1383-97.

18. Kane GC, Xu N, Mistrik E, Roubicek T, Stanson AW, Garovic VD. Renal artery revascularization improves heart failure control in patients with atherosclerotic renal artery 
stenosis. Nephrol Dial Transpl. 2010;25:813-820.

19. Textor SC. Despite Results from ASTRAL, Jury Still Out on Stenting for Atherosclerotic Renal Artery Stenosis. Nephrology Times. 2010;3(1):2-7.

20. Bavry AA, Kapadia SR, Bhatt DL, Kumbhani DJ. Renal Artery Revascularization, Updated Meta-analysis With the CORAL Trial. JAMA Intern Med. 2014;174(11):1849-1851.

21. Marcantoni C, Zanoli L, Rastelli S, Tripepi G, Matalone M, Mangiafico S,

Capodanno D, Scandura S, Di Landro D, Tamburino C, Zoccali C, Castellino P. Effect of Renal Artery Stenting on Left Ventricular Mass: A Randomized Clinical Trial. Am J Kidney Dis. 2012;60(1):39-46.

22. Wright JR, Shurrab AE, Cooper A, Kalra PR, Foley RN, Kalra PA. Progression of cardiac dysfunction in patients with atherosclerotic renovascular disease. QJM. 2009;102:695-704.

23. Zeller T, Rastan A, Schwarzwälder U, Müller C, Frank U, Bürgelin K, Sixt S, Schwarz T, Noory E, Neumann F-J. Regression of left ventricular hypertrophy following stenting of renal artery stenosis. J Endovasc Ther. 2007;14:189-197. 


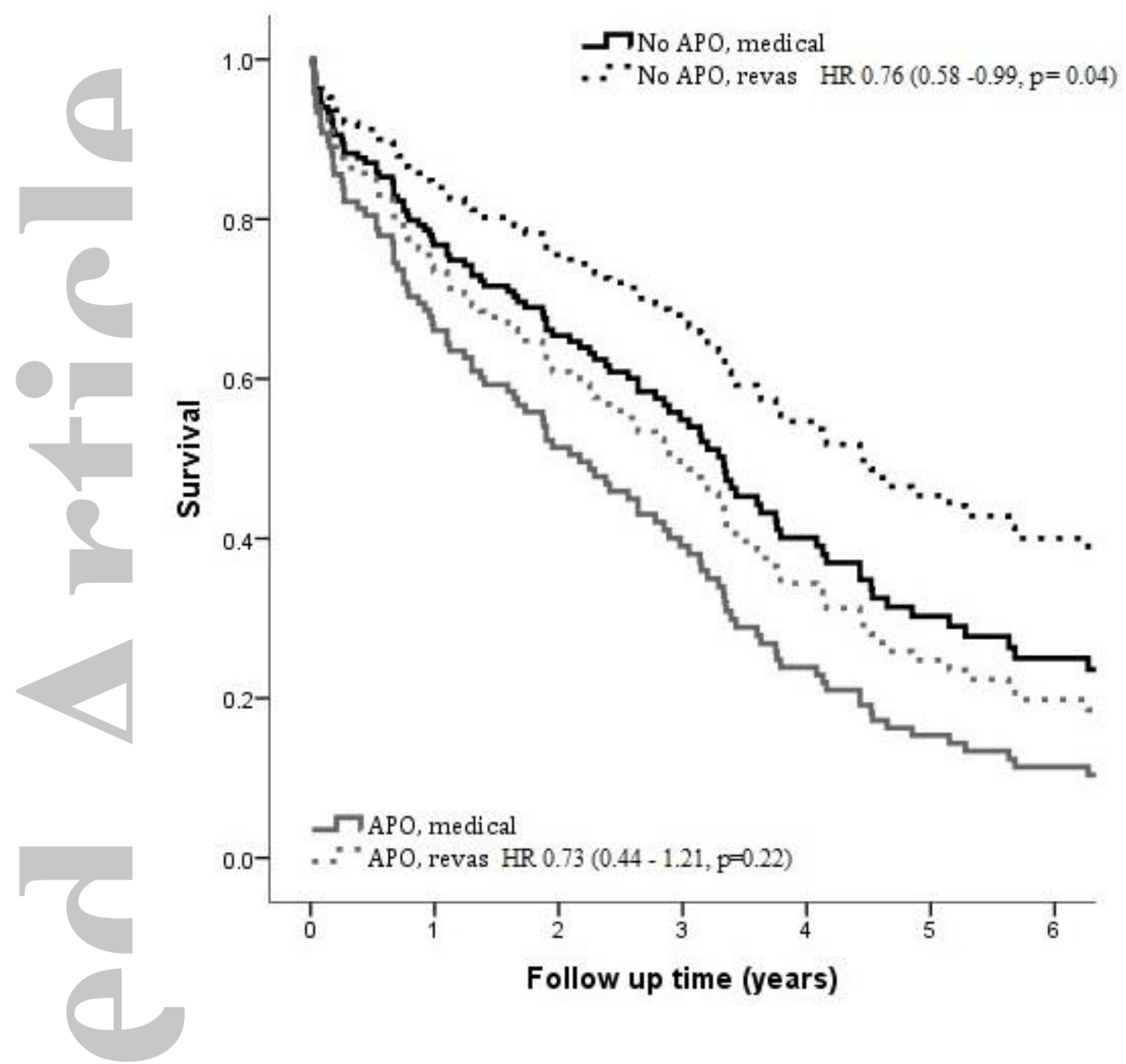

Figure 1. Survival curves for all-cause mortality in patients with atherosclerotic renal artery stenosis and heart failure, comparing revascularization versus medical therapy divided into those with and without previous acute pulmonary oedema and adjusted for age, renal function, systolic blood pressure, coronary artery disease, smoking, diabetes mellitus, and patency score.

$A P O=$ acute pulmonary oedema, Revasc $=$ revascularization. 
Table 1. Baseline cohort characteristics.

\begin{tabular}{|c|c|c|c|c|c|c|c|c|}
\hline & \multicolumn{4}{|c|}{ Heart failure, no APO } & \multicolumn{4}{|c|}{ Heart failure with APO } \\
\hline & Overall & Medical & Revas & $\mathbf{p}$ & Overall & Medical & Revas & $\mathbf{p}$ \\
\hline \multicolumn{9}{|l|}{ Demographics } \\
\hline $\mathrm{N}$ & 100 & 69 & 31 & - & 52 & 36 & 16 & - \\
\hline Age (years) & $71 \pm 9$ & $72 \pm 9$ & $69 \pm 9$ & 0.22 & $70 \pm 7$ & $72 \pm 7$ & $64 \pm 7$ & 0.01 \\
\hline Male gender (\%) & 66 & 67 & 65 & 0.82 & 46 & 51 & 31 & 0.24 \\
\hline \multicolumn{9}{|c|}{ Cardiovascular co-morbidities } \\
\hline $\operatorname{LVEF}(\%)$ & $42 \pm 13$ & $44 \pm 12$ & $39 \pm 16$ & 0.58 & $47 \pm 12$ & $47 \pm 12$ & $48 \pm 13$ & 0.86 \\
\hline Systolic BP (mmHg) & $149 \pm 32$ & $146 \pm 32$ & $156 \pm 32$ & 0.17 & $158 \pm 30$ & $155 \pm 30$ & $165 \pm 30$ & 0.26 \\
\hline Previous MI (\%) & 50 & 54 & 42 & 0.28 & 26 & 24 & 31 & 0.74 \\
\hline Diabetes $(\%)$ & 39 & 38 & 42 & 0.82 & 30 & 30 & 31 & 1.00 \\
\hline Smoker $(\%)$ & 33 & 33 & 32 & 0.43 & 61 & 63 & 57 & 0.92 \\
\hline \multicolumn{9}{|l|}{ RAS severity } \\
\hline $\mathrm{eGFR}\left(\mathrm{mL} / \mathrm{min} / 1.73 \mathrm{~m}^{2}\right)$ & $27 \pm 15$ & $27 \pm 16$ & $27 \pm 13$ & 0.93 & $28 \pm 19$ & $27 \pm 21$ & $31 \pm 15$ & 0.54 \\
\hline Bilateral RAS (\%) & 55 & 51 & 65 & 0.38 & 52 & 51 & 56 & 0.75 \\
\hline Occlusive RAS (\%) & 33 & 35 & 29 & 0.85 & 31 & 35 & 19 & 0.49 \\
\hline Patency score & $88 \pm 47$ & $94 \pm 46$ & $73 \pm 50$ & 0.04 & $89 \pm 43$ & $93 \pm 40$ & $78 \pm 50$ & 0.26 \\
\hline \multicolumn{9}{|l|}{ Concurrent medication } \\
\hline RAAS use (\%) & 50 & 55 & 39 & 0.19 & 34 & 41 & 13 & 0.09 \\
\hline Statin use (\%) & 56 & 54 & 61 & 0.52 & 46 & 49 & 38 & 0.56 \\
\hline Anti-platelet use (\%) & 39 & 38 & 42 & 0.83 & 56 & 62 & 44 & 0.32 \\
\hline
\end{tabular}

Key: $A P O=$ acute pulmonary oedema; revas $=$ revascularization $;$ LVEF = left ventricular ejection fraction; $B P=$ blood pressure; $M I=$

myocardial infarction; eGFR = estimated glomerular filtration rate; $R A S=$ renal artery stenosis; $R A A S=$ renin-angiotensin-aldosterone

system.

This article is protected by copyright. All rights reserved. 
Table 2. Primary indications for revascularization.

\begin{tabular}{l|cc|cc}
\hline & \multicolumn{2}{|c|}{ Heart failure, no APO } & \multicolumn{2}{|c}{ Heart failure with APO } \\
\cline { 2 - 5 } & $\mathrm{n}$ & $\%$ & $\mathrm{n}$ & $\%$ \\
\hline Hypertension & 10 & $(32)$ & 2 & $(12.5)$ \\
\hline Acute pulmonary oedema & 0 & - & 12 & $(75)$ \\
\hline Heart failure & 6 & $(19)$ & 0 & - \\
\hline Decline in renal function & 5 & $(16)$ & 2 & $(12.5)$ \\
\hline ACE inhibitor intolerance & 5 & $(16)$ & 0 & - \\
\hline Clinical trial & 5 & $(16)$ & 0 & - \\
\hline Total & 31 & $(100)$ & 16 & $(100)$ \\
\hline
\end{tabular}

Key: $A P O=$ acute pulmonary oedema 
Table 3. Hazard ratio (HR) for outcome in patients undergoing renal artery revascularization versus medical therapy, adjusted for age, renal function, systolic blood pressure, coronary artery disease, smoking, diabetes mellitus, and concurrent medication.

\begin{tabular}{|c|c|c|c|c|c|}
\hline & \multirow{2}{*}{ HR } & \multirow{2}{*}{$95 \% \mathrm{CI}$} & \multirow{2}{*}{$\mathbf{p}$} & \multicolumn{2}{|c|}{ Events, n (\%) } \\
\hline & & & & Medical & Revasc \\
\hline \multicolumn{6}{|c|}{ All-cause mortality } \\
\hline $\mathrm{HF}$, no APO & 0.76 & $0.58-0.99$ & 0.04 & $57(83)$ & $22(71)$ \\
\hline HF with APO & 0.73 & $0.44-1.21$ & 0.22 & $30(81)$ & $10(63)$ \\
\hline \multicolumn{6}{|c|}{ Heart failure hospitalization } \\
\hline $\mathrm{HF}$, no APO & 1.00 & $0.17-6.05$ & 1.00 & $6(9)$ & $2(6)$ \\
\hline HF with APO & 0.51 & $0.08-3.30$ & 0.48 & $4(11)$ & $1(6)$ \\
\hline \multicolumn{6}{|c|}{ Fatal and non-fatal cardiovascular events } \\
\hline $\mathrm{HF}$, no APO & 0.98 & $0.44-2.18$ & 0.96 & $26(38)$ & $12(39)$ \\
\hline HF with APO & 0.62 & $0.31-1.27$ & 0.19 & $15(41)$ & $6(38)$ \\
\hline
\end{tabular}

Key: $H F=$ heart failure; $A P O=$ acute pulmonary oedema. 
Table 4. Causes of death and cardiovascular events expressed as a percentage of patients in each category.

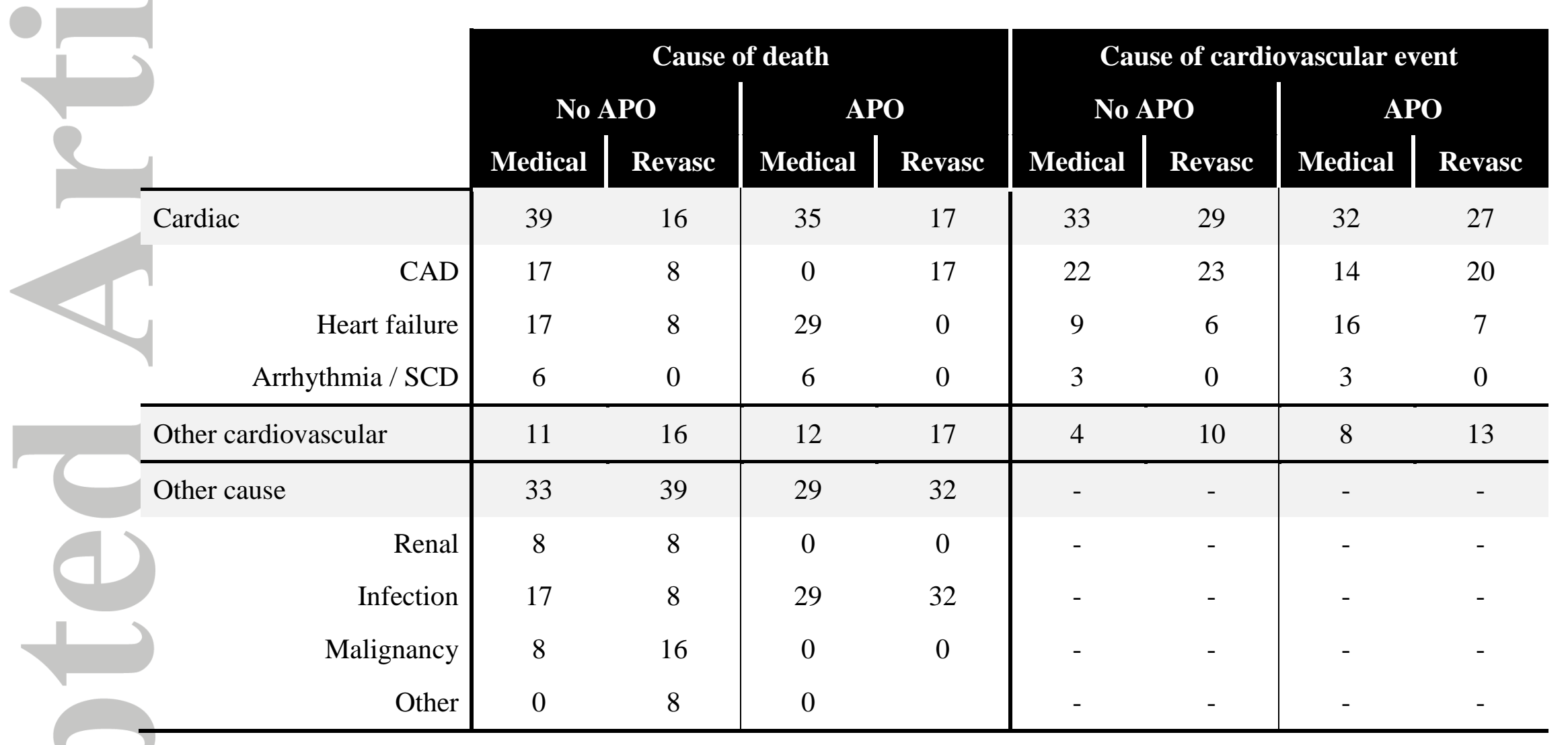

Key: $A P O=$ acute pulmonary oedema, $C A D=$ coronary artery disease, $S C D=$ sudden cardiac death. 